DOI: https://doi.org/10.24867/02EF02Bubnjevic

\title{
EKOLOŠKI UTICAJ MANGANA NA GRAFIČKO OKRUŽENJE
}

\section{THE ECOLOGICAL IMPACT OF MANGANESE ON THE PRINTING ENVIRONMENT}

\author{
Milica Bubnjević, Savka Adamović, Miljana Prica, Fakultet tehničkih nauka, Novi Sad
}

\section{Oblast - GRAFIČKO INŽENJERSTVO I DIZAJN}

Kratak sadržaj - Ekološki uticaj mangana na grafičko okruženje utvrđen je kroz određivanje sadržaja mangana u štampanim ofset uzorcima i migracije mangana iz uzoraka $u$ deponijsko tlo, kiseo i neutralan rastvor. Takođe, izvršenaje i procena rizika migracije mangana određivanjem doze koja je dospela u medij životne sredine.

Ključne reči: Grafičko okruženje, Ofset štampa, Mangan, Migracija, Procena rizika

\begin{abstract}
The ecological impact of manganese on the printing environment was determined by measuring of concentration levels of manganese in printed offset samples and migrations of manganese from printed samples into landfill, acidic and neutral solution. Also, the assessment of migration risk of manganese to the environment was evaluated.
\end{abstract}

Keywords: Printing environment, Offset printing, Manganese, Migration, Risk assessement

\section{UVOD}

U grafičkoj proizvodnji tokom procesa pripreme, štampe i obrade potroše se ogromne količine materijala, ali se i generišu relativno visoki nivoi otpada (čvrstog, tečnog i gasovitog) koji mogu sadržati zagađujuće materije. Pored toga što zagađujuće materije imaju potencijalno negativan uticaj na zaposlene u štampariji, one dospevaju i utiču na životnu sredinu.

Složenost tehnološkog grafičkog procesa dovodi do nepoštovanja prevencije, kao prvog pravila hijerarhije u zaštiti životne sredine, zbog čega je neophodno izvršiti adekvatnu reciklažu i odlaganje otpadnih produkata grafičke proizvodnje [1]. Zbog nedostatka adekvatnih reciklažnih pogona, štampani uzorci najčešće završavaju na komunalnom ili divljem deponijskom tlu, te je potrebno utvrditi kako njihovo razlaganje utiče na zemljište.

Mangan je prelazni hemijski element, oznake Mn i atomskog broja 25. Mn ima 15 izotopa, od kojih je postojan samo izotop čiji je maseni broj 55 i on čini gotovo $100 \%$ sastava izotopa Mn koji se javlja u prirodi [2]. Mn je široko rasprostranjen u stenama, zemljištu i vodu [3] i od vitalnog je značaja za metaboličke funkcije kako ljudi tako i drugih živih bića [4].

Mangan je i industrijska sirovina, pa se tako u grafičkoj proizvodnji upotrebljava kao konstituent ofset štamparskih

\section{NAPOMENA:}

Ovaj rad proistekao je iz master rada čiji mentor je bila dr Savka Adamović, docent. formi, ofset, tipo i sito grafičkih boja (kao crni pigment i najčešće sikativ) i lakova [5]. Sa aspekta zaštite životne sredine, Mn dugo nije bio predmet zabrinutosti, ali se to polako menja.

Mangan jeste esencijalni element, ali može da pokazuje ekotoksični efekat (štetan ili rizičan hemijski, biološki ili fizički uticaj) na ekosistem. Što se tiče kancerogenog efekta, ne postoji dokaz o kancerogenosti Mn po ljudski organizam, dok su izveštaji o kancerogenosti po životinjski organizam nepotpuni i neadekvatni. Bez obzira na vrstu efekta, procena rizika Mn je neophodna jer se njom mogu obuhvatiti: (1) procena efekta kroz identifikaciju negativnih efekata koje Mn može da izazove, i određivanje doze Mn, (2) procena izloženosti kroz određivanje doze Mn kojoj su bili izloženi ljudi ili doze koja je dospela u neki medij životne sredine (voda, vazduh ili zemljište) i karakterizaciju rizika [6].

Cilj rada je procena ekološkog uticaja Mn na grafičko okruženje na osnovu monitoringa migracije $\mathrm{Mn}$ iz štampanih ofset uzoraka (plakata i novina) u dve faze: tečnu (rastvori pH vrednosti 3,25 i 7) i čvrstu (komunalna i divlja deponijska zemlja) tokom 60 dana. Takođe, ekološki uticaj $\mathrm{Mn}$ definisan je kroz procenu rizika migracije $\mathrm{Mn}$ iz štampanih ofset uzoraka određivanjem doze koja je dospela u medij životne sredine.

\section{EKSPERIMENTALNI DEO}

\subsection{Karakterizacija ofset štampanih uzoraka}

Prvi ispitivani uzorak je plakat štampan tabačnom tehnikom ofset štampe u Grafičkom centru Departmana za grafičko inženjerstvo i dizajn na Fakultetu tehničkih nauka, Univerziteta u Novom Sadu. Za dobijanje finalnog grafičkog proizvoda upotrebljeni su: procesne cijan, magenta, žuta i crna (CMYK) boje za tabačnu ofset štampu (proizvođač TOYO INK CO., LTD., Japan), premazni sjajni papir (gramature $120 \mathrm{~g} / \mathrm{m}^{2}$ ) i mašina za tabačnu ofset štampu KBA Rapida 75 4/0 (proizvođač Koenig \& Bauer Group, Nemačka).

Drugi ispitivani uzorak su novine novosadskog dnevnog lista, štampane rotacionom tehnikom ofset štampe. Za štampu novina upotrebljeni su: procesne CMYK boje za rotacionu štampu (proizvođač Schuite \& Schuite Druckfarben, Nemačka), roto novinski papir (gramature $45 \mathrm{~g} / \mathrm{m}^{2}$ ) i mašina za rotacionu ofset štampu Mediaman (proizvođač MAN Roland, Nemačka).

\subsection{Određivanje sadržaja Mn u štampanim uzorcima}

2,5 g usitnjenog plakata i $1 \mathrm{~g}$ usitnjenih novina odmereni su u lončićima za žarenje poznate mase. Prazni lončići za žarenje su prethodno ižareni $6 \mathrm{~h}$ na $500^{\circ} \mathrm{C}$ u peći za žarenje, ohlađeni u eksikatoru, a masa im je određena na tehničkoj 
vagi PS 2100/C2 (RADWAG, Poljska) sa tačnošču $\pm 0,01$ g. Po dodatku $5 \mathrm{ml} \mathrm{Mg}\left(\mathrm{NO}_{3}\right)_{2}$ (p.a., Merck, Nemačka) u etanolu (p.a., Alkaloid, Skoplje), sadržaji lončića za žarenje su spaljivani na rešou do prestanka izdvajanja žutih para azotovih oksida, a potom žareni u peći za žarenje $4 \mathrm{~h}$ na $450^{\circ} \mathrm{C}$ (prvo žarenje). Posle prvog žarenja uzorci su hlađeni u eksikatoru. Uzorcima je dodato $1 \mathrm{ml}(2: 1) \mathrm{HNO}_{3}$ (p.a., Merck, Nemačka) i 0,5 ml cc $\mathrm{H}_{2} \mathrm{O}_{2}$ (p.a., Centrohem, Srbija) i ponovljen je postupak rešo - peć za žarenje $1 \mathrm{~h}$ na $450^{\circ} \mathrm{C}$ (drugo žarenje).

Posle drugog žarenja uzorci pepela su hlađeni u eksikatoru, rastvarani u $5 \mathrm{ml} \mathrm{10 \%} \mathrm{HCl}$ (p.a., Merck, Nemačka), kvantitativno filtrirani preko levka i filter papira (MACHEREY-NAGEL, Nemačka) u normalne sudove od $25 \mathrm{ml}$ i dopunjeni dejonizovanom vodom. Koncentracije $\mathrm{Mn}$ u pripremljenim rastvorima određene su na atomskom absorpcionom spektrofotometru, AAS (Thermo Scientific 75 SOLAAR S serije AA spectrometer), plamenom tehnikom u skladu sa USEPA 7000b metodom. Masene koncentracije $\mathrm{Mn} \mathrm{u}$ jedinicama $\mathrm{mg} / \mathrm{kg}$ u plakatu i novinama izračunate su prema formuli (1) [7]:

$$
\gamma=\frac{C \cdot V}{m}
$$

gde su: $\gamma$ - masena koncentracija Mn u štampanom ofset uzorku (mg/kg), C - količinska koncentracija Mn u rastvoru $(\mathrm{mg} / \mathrm{l}), \mathrm{V}$ - zapremina rastvora $(\mathrm{ml}) \mathrm{i} \mathrm{m}$ - masa štampanog ofset uzorka $(\mathrm{g})$.

\subsection{Migracija Mn iz štampanih ofset uzoraka}

U eksperimentu praćena je migracija Mn iz plakata i novina u dve faze: tečnu (rastvori pH vrednosti 3,25 i 7) i čvrstu (komunalna i divlja deponijska zemlja).

pH vrednost simulanta rastvora kiselih kiša $(3,25)$ podešena je dodavanjem cc $\mathrm{HCl}$ (p.a., 36\%, Merck, Nemačka) u dejonizovanu vodu. Za neutralan rastvor upotrebljena je dejonizovana voda. $\mathrm{pH}$ vrednosti neutralnog i rastvora kiselih kiša izmerena je digitalnim $\mathrm{pH}$ metrom (model PHD 21, DECODE, SR Jugoslavija).

Uzorak komunalne deponijske zemlje uzet je sa gradske deponije Novi Sad koja se nalazi u severnom delu građevinskog područja grada Novog Sada, severno od autoputa E-75. Uzorak zemlje sa divlje deponije uzet je u novosadskom prigratskom naselju Kać (koordinate 4518'09"N/19'56'19"E). Uzorci komunalne i divlje deponiske zemlje sušeni su u sušnici na $105^{\circ} \mathrm{C}$ do konstantne mase.

Za test migraciju, u laboratorijske čaše od $200 \mathrm{ml}$ prvo je odmereno na tehničkoj vagi $20 \mathrm{~g}$ deponijske zemlje (komunalne ili divlje), a potom $5 \mathrm{~g}$ usitnjenih ofset uzorka. Uzorci sa odgovarajućom deponijskom zemljom i štampanim ofset uzorcima potapani su u $100 \mathrm{ml}$ neutralnog rastvora $(\mathrm{pH}=7,0)$ i $100 \mathrm{ml}$ rastvora simulanta kiselih kiša $(\mathrm{pH}=3,25)$. Sprovedeno je 60. dnevno testiranje, a analize Mn u uzorcima komunalne i divlje deponijske zemlje sprovedene su 1., 2., 3., 4., 5., 10., 20., 30., 40., 50. i 60. dana na sobnoj temperaturi. $U$ navedenim danima filtracijom preko kvantitativnog filter papira (MACHEREYNAGEL, Nemačka) razdvojene su tečna i čvrsta faza (komunalna ili divlja deponijska zemlja). Potom je kiseo ili neutralan filtrat pripremljen za analizu sadržaja Mn: $20 \mathrm{ml}$ filtrata koncentrisano je do zapremine od 1 do $2 \mathrm{ml}$, a zatim

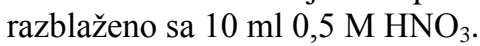

Kiselom digestijom određen je sadržaj Mn u komunalnoj i divljoj deponijskoj zemlji pre kontakta (inicijalna koncentracija Mn) i nakon određenog dana kontakta deponijske zemlje, ofset uzorka i rastvora odgovarajuće $\mathrm{pH}$ vrednosti.

Koncentracije Mn u pripremljenim uzorcima određene su na atomskom absorpcionom spektrofotometru, AAS (Thermo Scientific - 75 SOLAAR S serije AA spectrometer), plamenom tehnikom u skladu sa USEPA 7000b metodom. Masene koncentracije $\mathrm{Mn} \mathrm{u}$ deponijskim zemljama izračunate su primenom formule (1).

\subsection{Procena rizika migracije Mn}

Za izračunavanje indeksa rizika za nekancerogene supstance (NCHI) upotrebljena je formula (2) [6].

$$
N C H I=\frac{C \cdot C r \cdot E f \cdot E d}{B w \cdot A t \cdot R f D}
$$

gde su: C - migrirane koncentracije Mn iz uzoraka, $\mathrm{Cr}$ - stepen izloženosti $\left(0,05 \mathrm{dm}^{3} / \mathrm{dan}\right)$, Ef - učestalost izlaganja (300 dana/god), Ed - trajanje izloženosti (30 god), Bw - telesna težina (70 kg, srednja težina za odrasle), At - srednje vreme izloženosti $(70$ god $=25550$ dana $) \mathrm{i}$ RfD - referantna doza za oralnu ekspoziciju za Mn $(0,14$ $\mathrm{mg} / \mathrm{kg} /$ dan za odraslog čoveka od $70 \mathrm{~kg}$ ).

\section{REZULTATI I DISKUSIJA}

Inicijalne masene koncentracije $\left(\gamma_{\mathrm{o}}\right) \mathrm{Mn} \mathrm{u}$ štampanim ofset uzorcima, kao i u komunalnoj i divljoj deponijskoj zemlji prikazane su u tabeli 1. Dobijeni rezultati pokazuju da divlja deponijska zemlja u odnosu na komunalnu ima 36\% veći sadržaj Mn. Takođe, novine u odnosu na plakat imaju 23\% veći sadržaj Mn (tabela 1).

Tabela 1. $\gamma_{o}$ Mn u štampanim ofset uzorcima, komunalnoj $i$ deponijskoj zemlji

\begin{tabular}{|c|c|c|c|c|}
\hline Uzorak & $\mathrm{C}_{\mathrm{o}}(\mathrm{mg} / \mathrm{l})$ & $\mathrm{m}(\mathrm{g})$ & $\mathrm{V}(\mathrm{ml})$ & $\gamma_{\mathrm{o}}(\mathrm{mg} / \mathrm{kg})$ \\
\hline Komunalna & 6,538 & 1 & 50 & 326,9 \\
\hline Divlja & 10,17 & 1 & 50 & 508,5 \\
\hline Plakat & 8,13 & 2,5 & 25 & 81,3 \\
\hline Novine & 4,2 & 1 & 25 & 105,0 \\
\hline
\end{tabular}

\subsection{Migracija Mn iz novina}

Priraštaji masenih koncentracija Mn iz novina u kiselu i neutralnu komunalnu deponijsku zemlju su u intervalima od 12,8 do $154,8 \mathrm{mg} / \mathrm{kg}$ i od 31,3 do $128,1 \mathrm{mg} / \mathrm{kg}$, respektivno. Od 1. do 60. dana migracije, uočava se povećanje od $91,7 \%$ za kiselu i od 75,6\% za neutralnu komunalnu deponijsku zemlju. Kada se uporede priraštaji u komunalne deponijske zemlje različite $\mathrm{pH}$ vrednosti, uočava se da su priraštaji Mn od 1. do 30. dana migracije viši od 59,1 do $76,6 \%$ u neutralnu komunalnu deponijsku zemlju, dok su od 40. do 60. dana migracije viši $17,2 \%$ u kiselu komunalnu deponijsku zemlju.

Priraštaji masenih koncentracija Mn iz novina u kiselu i neutralnu divlju deponijsku zemlju su u intervalima od 35,0 do $315,0 \mathrm{mg} / \mathrm{kg}$ i od 39,0 do $294,5 \mathrm{mg} / \mathrm{kg}$. Od 1. do 60. dana migracije, uočava se povećanje od $88,9 \%$ za kiselu i od 
$86,8 \%$ za neutralnu divlju deponijsku zemlju. Kada se uporede priraštaji $\mathrm{Mn}$ u divlje deponijske zemlje različite $\mathrm{pH}$ vrednosti, uočava se da su priraštaji Mn od 1. do 30 . dana migracije viši od 10,3 do $25,3 \%$ u neutralnu divlju deponijsku zemlju, dok su od 40. do 60. dana migracije viši $6,5 \%$ u kiselu komunalnu deponijsku zemlju.

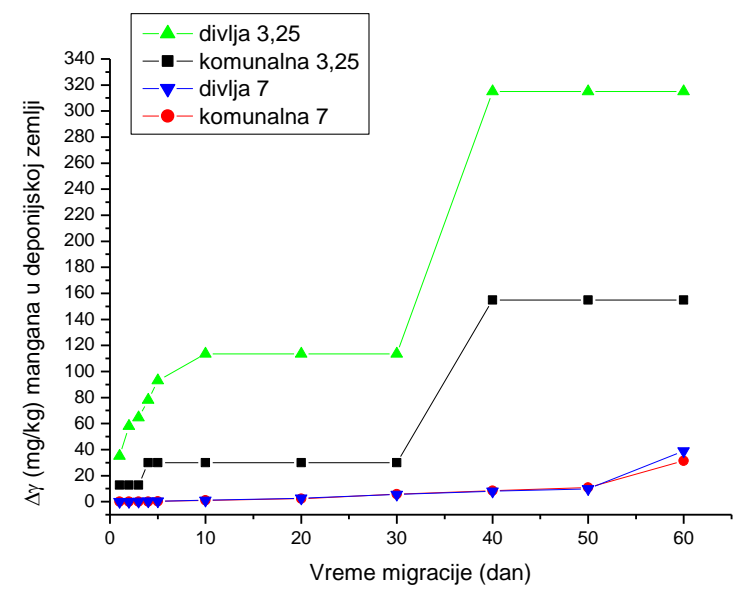

Slika 1. Priraštaji masenih koncentracija Mn iz novina $u$ komunalnu i divlju deponijsku zemlju tokom 60 dana migracije

Analizirajući uticaj vrste deponijske zemlje i njenje pH vrednosti uočava se da priraštaji masenih koncentracija Mn tokom 60 dana kontakta novina i odgovarajućeg uzorka deponijske zemlje opadaju u nizu: kisela divlja > kisela komunalna $>$ neutralna komunalna $\sim$ neutralna divlja deponijska zemlja (slika 1).

Za migraciju Mn u rastvore različitih $\mathrm{pH}$ vrednosti iz novina na komunalnoj deponijskoj zemlji uočava se da su koncentracije Mn tokom 60 dana migracije u kiseo rastvor u intervalu od 1,374 do $14,090 \mathrm{mg} / \mathrm{l}$, dok su za neutralni rastvor u intervalu od 0,016 do $11,570 \mathrm{mg} / \mathrm{l}$ i da su najveće $\mathrm{i}$ najmanje migrirane koncentracije $\mathrm{Mn} \mathrm{u}$ kiseo rastvor $\mathrm{u}$ odnosu na neutralan rastvor veće 17,9 i 98,8\%, respektivno.

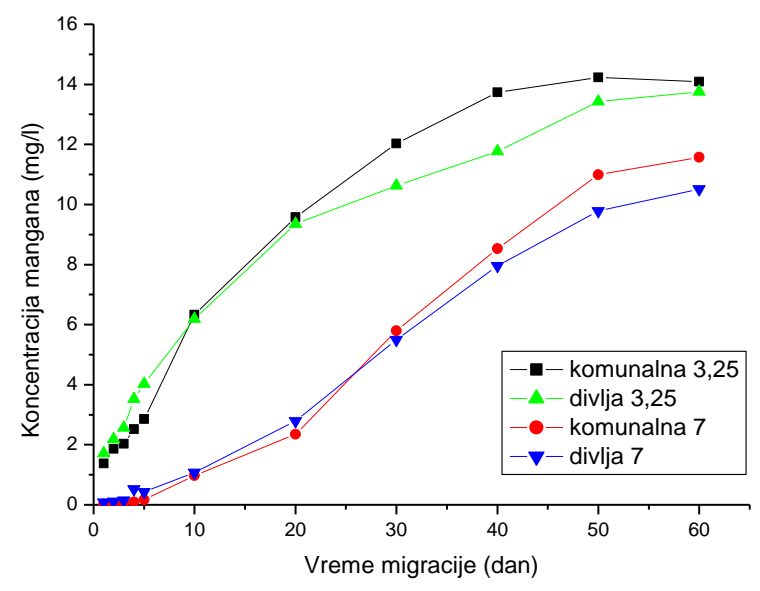

Slika 2. Migracione koncentracije Mn iz štampanih novina na komunalnoj i divljoj deponijskoj zemlji u kiseo $i$ neutralan rastvor tokom 60 dana

Koncentracije Mn tokom 60 dana migracije u kiseo rastvor iz novina na divljoj deponijskoj zemlji su u intervalu od 1,709 do $13,750 \mathrm{mg} / \mathrm{l}$, dok su za neutralni rastvor u intervalu od 0,087 do $10,510 \mathrm{mg} / \mathrm{l}$. Najveće i najmanje migrirane koncentracije $\mathrm{Mn}$ u kiseo rastvor u odnosu na neutralan rastvor su veće 23,6 i 94,9\%, respektivno.

Dobijeni rezultati pokazuju da sa povećanjem vremena kontakta smanjuje se razlika između koncentracija migracije Mn u kiseo i neutralan rastvor iz novina na komunalnoj i divljoj deponijskoj zemlji.

Analizirajući uticaj $\mathrm{pH}$ vrednosti rastvora na migraciju Mn iz novina na komunalnoj i divljoj deponijskoj zemlji ne uočava se ista zavisnost tokom svih 60 dana (slika 2). Tek se od 30. do 60. dana uočava ista zavisnost, koja opada $u$ nizu: kiseli rastvor komunalna > kiseli rastvor divlja > neutralni rastvor komunalna > neutralni rastvor divlja deponijska zemlja.

\subsection{Migracija Mn iz plakata}

Za migraciju Mn iz plakata priraštaji masenih koncentracija $\mathrm{u}$ kiselu i neutralnu komunalnu deponijsku zemlju su u intervalima od 67,3 (2. dan) do $143,7 \mathrm{mg} / \mathrm{kg}$ i od 5,1 do $124,8 \mathrm{mg} / \mathrm{kg}$, respektivno. Od 1. do 60. dana migracije, uočava se povećanje od $53,2 \%$ za kiselu i od $95,9 \%$ za neutralnu komunalnu deponijsku zemlju. Uočava se da 1. dana dolazi do migracije Mn iz plakata samo u neutralnu komunalnu deponijsku zemlju. Od 2. do 4. dana migracije, priraštaji Mn u kiseloj viši su u intervalu od 45,3 do 26,4\%, dok su 5. dana migracije $27,0 \%$ viši u neutralnoj u odnosu na priraštaj u kiseloj deponijskoj zemlji. Nakon toga, od 10. do 60. dana migracije priraštaji Mn iz plakata su konstantni i viši $13,1 \%$ u kiseloj u odnosu na neutralnu komunalnu deponijsku zemlju.

Priraštaji masenih koncentracija Mn iz plakata u kiselu i neutralnu divlju deponijsku zemlju su u intervalima od 84,0 (3. dan) do $134,0 \mathrm{mg} / \mathrm{kg}$ i od 25,5 do $125,5 \mathrm{mg} / \mathrm{kg}$. Od 3 . do 60. dana migracije, uočava se povećanje od 37,3\% za kiselu i od $79,7 \%$ za neutralnu divlju deponijsku zemlju. Dobijeni rezultati pokazuju da od 3 . do 60 . dana migracije priraštaji Mn u kiselu u odnosu na neutralnu divlju deponijsku zemlju su viši u intervalu od 26,2 do 6,3\%. Kao i kod novina i kod plakata uočava se da sa povećanjem vremena kontakta plakata i divlje deponijsake zemlje različitih $\mathrm{pH}$ vrednosti razlika između priraštaja se smanjuje.

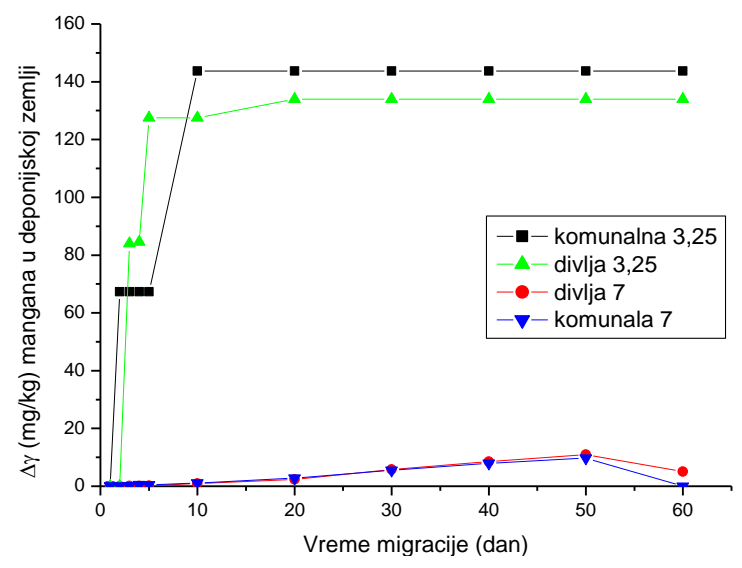

Slika 3. Priraštaj masenih koncentracija Mn iz plakata u komunalnu i divlju deponijsku zemlju tokom 60 dana migracije

Analizirajući uticaj vrste deponijske zemlje i njene $\mathrm{pH}$ vrednosti uočava se da priraštaji masenih koncentracija Mn od 1. do 5. dana kontakta plakata i odgovarajućeg uzorka deponijske zemlje opadaju u nizu: kisela divlja > kisela 
komunalna > neutralna divlja neutralna komunalna deponijska zemlja. Od 10. do 60. dana uočava se pad priraštaja masenih koncentracija mangana u nizu: kisela komunalna > kisela divlja > neutralna komunalna neutralna divlja deponijska zemlja (slika 3).

$\mathrm{Za}$ migraciju $\mathrm{Mn}$ u rastvore različitih $\mathrm{pH}$ vrednosti iz plakata na komunalnoj deponijskoj zemlji uočava se da koncentracije migracije u kiseo i neutralni rastvor prvo rastu, a potom opadaju. Najveće i najmanje migrirane koncentracije $\mathrm{Mn}$ u kiseo rastvor u odnosu na neutralan rastvor veće su 73,7\% i 98,6\%, respektivno.

$\mathrm{Za}$ migraciju $\mathrm{Mn} \mathrm{u}$ rastvore različitih $\mathrm{pH}$ vrednosti iz plakata na divljoj deponijskoj zemlji uočava se da koncentracije migracije $u$ kiseo i neutralni rastvor prvo rastu (do 50. dana), a potom opadaju, i da su najveće i najmanje migrirane koncentracije $\mathrm{Mn} \mathrm{u}$ kiseo rastvor u odnosu na neutralan rastvor veće $69,0 \%$ i 99,4\%, respektivno.

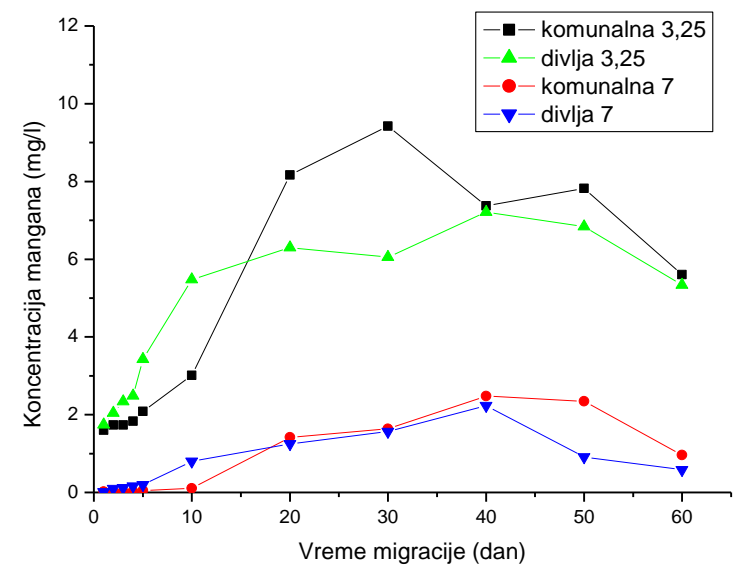

Slika 4. Migracione koncentracije Mn iz štampanog plakata na komunalnoj i divljoj deponijskoj zemlji u kiseo $i$ neutralan rastvor tokom 60 dana

Analizirajući uticaj pH vrednosti rastvora na migraciju Mn iz plakata na komunalnoj i divljoj deponijskoj zemlji u kiseo i neutralan rastvor ne uočava se ista zavisnost tokom svih 60 dana. Tek od 20. do 60. dana uočava se ista zavisnost koja opada u nizu: kiseli rastvor komunalna > kiseli rastvor divlja > neutralni rastvor komunalna > neutralni rastvor divlja deponijska zemlja (slika 4).

\subsection{Procena rizika migracije mangana iz štampanih ofset uzoraka}

Uz predpostavku da je došlo do kontakta deponijskih, podzemnih i pijaćih voda određen je nekancerogeni rizik unosa Mn iz pijaće vode. Dobijeni rezultati pokazuju da su nekancerogeni hazardni indeksi unosa mangana, NCHI (Mn) u neutralnoj u odnosu na kiselu sredinu niži: od 1,2 do 68,9 puta (novine na komunalnoj deponijskoj zemlji), od 1,3 do 19,1 puta (novine na divljoj deponijskoj zemlji), od 15,7 do 75,8 puta (plakat na komunalnoj deponijskoj zemlji) i od 1,4 do 151,5 puta (plakat na divljoj deponijskoj zemlji). Takođe, izračunati NCHI (Mn) su manji od 0,1 i ne predstavljaju rizik po zdravlje čoveka.

\section{ZAKLJUČAK}

Na osnovu kvantifikovanih priraštaja masenih koncentracija Mn iz novina zaključuje se da vrsta i pH vrednost deponijske zemlje utiču na migraciju Mn iz novina. Veći su priraštaji migracije Mn u divlju u odnosu na komunalnu deponijsku zemlju iste $\mathrm{pH}$ vrednosti. Takođe, niža $\mathrm{pH}$ vrednost povećava priraštaj migracije za istu vrstu deponijske zemlje.

I kod plakata se uočava da niža $\mathrm{pH}$ vrednost povećava priraštaj migracije za istu vrstu deponijske zemlje.Veći su priraštaji migracije $\mathrm{Mn}$ iz plakata u kiselu komunalnu u odnosu na kiselu divlju deponijsku zemlju. Priraštaji migracije Mn iz plakata u neutralnu divlju veći su u odnosu na neutralnu komunalnu deponijsku zemlju.

Analiza uticaja $\mathrm{pH}$ vrednosti rastvora na migraciju $\mathrm{Mn}$ iz novina i plakata na komunalnoj i divljoj deponijskoj zemlji, pokazuje da su vrednosti migracije Mn u kiseo rastvor veće $\mathrm{u}$ odnosu na iste $\mathrm{u}$ neutralni rastvor.

Najveće vrednosti priraštaja masenih koncentracija Mn, pokazuju da uticaj vrste štampanog ofset uzorka opada $\mathrm{u}$ nizu: novine kisela $(154,8 \mathrm{mg} / \mathrm{kg})>$ plakat kisela $(143,7$ $\mathrm{mg} / \mathrm{kg})>$ novine neutralna $(128,1 \mathrm{mg} / \mathrm{kg})>$ plakat neutralna $(124,8 \mathrm{mg} / \mathrm{kg})$ komunalna deponijska zemlja. Takođe, $\mathrm{pH}$ vrednost komunalne deponijske zemlje ima dominantan uticaj.

Kada se uporede najveće vrednosti priraštaja migracije Mn, uticaj vrste štampanog ofset uzorka opada u nizu: novine kisela $(315,0 \mathrm{mg} / \mathrm{kg})>$ novine bazna $(294,5 \mathrm{mg} / \mathrm{kg})>$ plakat kisela $(134,0 \mathrm{mg} / \mathrm{kg})>$ plakat bazna $(125,5 \mathrm{mg} / \mathrm{kg})$ divlja deponijska zemlja. Dakle, u slučaju divlje deponijske zemlje veći su priraštaji masenih koncentracija Mn iz novina.

S' obzirom da procedne deponijske vode dolaze u kontak sa podzemnim vodama, moguća je kontaminacija pijaćih voda sa Mn. Dobijeni rezultati pokazuju da su NCHI (Mn) niži u neutralnoj u odnosu na kiselu sredinu i da Mn u pijaćoj vodi dospeo i štampanih ofset uzoraka ne predstavlja rizik po zdravlje čoveka jer su NCHI (Mn) niži od 0,1 .

\section{LITERATURA}

[1] S. Adamović, "Elektrokoagulacioni i adsorpcioni tretmani efluenata u grafičkim procesima ofset štampe", doktorska disertacija, Fakultet tehničkih nauka, Novi Sad, 2016.

[2] http://www.pse.pbf.hr/hrvatski/elementi/mn/minerali_i _proizvodnja.html (pristupljeno u avgustu 2018.)

[3] http://www.who.int/ipcs/publications/cicad/cicad63_ rev_1.pdf (pristupljeno u avgustu 2018.)

[4] https://www.livescience.com/29247-manganese.html (pristupljeno u avgustu 2018.)

[5] M. Prica, S. Adamović, S. "Grafički materijali”, FTN Izdavaštvo, Novi Sad, 2017.

[6] http://helix.chem.bg.ac.rs/ grzetic/predavanja/Hemija $\% 20$ zivotne $\% 20$ sredine $\% 20$ II/UPRAVLJANJE\%20RI ZIKOM\%20I\%20NJEGOVA\%20PROCENA.pdf (pristupljeno u septembru 2018.)

[7] W.J. Price, "Spectrochemical Analysis by Atomic Absorption", Heyden \& Son, London, pp. 252-253, 1979.

\section{Adrese autora za kontakt:}

Milica Bubnjević - zoe.milica@gmail.com Doc.dr Savka Adamović - adamovicsavka@uns.ac.rs Van. prof. dr Miljana Prica - miljana@uns.ac.rs Grafičko inženjerstvo i dizajn, FTN, UNS. 